\title{
PERILAKU ORGANISASIONAL APARATUR DALAM AKSELERASI PEMBANGUNAN DAERAH
}

\author{
Oleh \\ Djihad Hisyam \\ FIS UNY
}

\section{Abstrak}

Aparatur pemerintah merupakan salah satu faktor yang perlu mendapat perhatian dalam rangka pembangunan daerah. Mereka adalah sumber daya yang harus diperdayakan dalam kapasitasnya untuk membangun suatu pemerintahan yang bersih dan berwibawa.

Dalam mewujudkan pemerintahan yang bersih dan berwibawa untuk akselerasi pembangunan diperlukan perilaku organisasional dari aparatur yang mendukung pada tujuan tersebut. Sehingga bentukbentuk penyelewengan negara dan berbagai penyakit birokrasi perlu direduksi dan dihindari. Sebagai bentuk "antisipasinya perlu mengupayakan berbagai strategi.

Salah satu usaha yang dilakukan adalah melakukan penyesuaian-penyesuaian dan perubahan perilaku yang mengarah pada pencapaian good goverment. Dalam hal ini faktor pemimpin mempunyai pengaruh yang besar untuk melakukan pembangunan bangsa.

Kata kunci: pembangunan, perilaku organisasional.

\section{Pendahuluan}

Pembangunan menjadi kata kunci bagi suatu negara yang ingin meningkatkan kesejahteraan warganya. Berbagai paradigma pembangunan sudah diperkenalkan untuk diimplementasikan dalam mendorong percepatan pembangunan, diantaranya melalui pendekatan: pembangunan partisipatif, pemberdayaan sumber daya daerah, new public menagement, capasity building, melalui buttom up planning, dll. Dalam upaya akselerasi pembangunan daerah, pemerintah juga telah memberi keleluasaan kepada masing-masing daerah dapat memberdayakan sumber daya yang dimilikinya untuk pembangunan daerahnya. Dengan diberlakukan Undang Undang Otonomi daerah maka pemda harus menggali potensi daerahnya dengan didukung oleh aparatur pemerintah yang profesional. 
Balah satu agen pembangunan adalah aparatur pemerintah sebagal abdl masyarakat bukan abr: ngara untuk mowujudkan pemerintalian yang berwibawa. Pembangunan akan beihasil kalau dalam pemerinIahan, seluruh perilaku organisasional para aparatur pemerintahan mampunyal komitmen untuk bekerja sacara profosional menuju pada tujuan negara yang dicita-citakan. Sehingoa berbagai penyakit birokrasi, penyelewengan terhadap negara dapat diantisipasi dan dihilangkan. Belapa fumlah uang negara yang semeslinya dapat dimanfaatkan untuk meningkatkan pembangunan beralih alokaginya untuk kepentingan pribad/kalompok sehingga negara banyak diruglkan. Seperti apa yang disampaikan oleh Koentjoroningrat dalail Modul SAKIP (2004) bahwa bangsa Indonesia mempunyai beberapa montalitot negatif yang tidak mendukung pembangunan bangsa Indonesia menjadi bangsa yang modein, leimasuk pembangunan aparaluf pemerintah. Mentalitet tersebut adalah menorabas (potong kompas), yang berarll ingin cepat selesai dan mentalltol merendahkan mutu, yang aflinya asal Jadi tanpa memperhilingkan kualitas. Korupsi yang terjaill di Indonosia menunjukkan jumlali yang lidak sedikit dibandingkan dengan negara lain. Menurut Dhothak Lallof dalam pidatonya pada diea Natalis FIS 2005 disampaikan baliwa talıun 2003 Indonesia men- duduki peringkat 122 dari 133 negara. Hal tersebut menjadi keprihatinan bagi bangsa yang sedang membangun.

Untuk menepis/mengurangi penyelewengan perilaku dan mengupayakan agar aparatur pemerintah mempunyai tanggung jawab dalam pembangunan maka perlu menekankan bagaimana seharusnya apartur berperilaku dalam organisasinya agar mengarah pada tanggung jawab dan kesadaran dalam ikut memberi kontribusi dalam pembangunan, terutama pembangunan daerah di mana mereka bekerja. Dalam hal ini faktor kepemimpinan daerah baik level kepememimpinan di jajaran eksekutif, legislatif maupun yudikatif sangat berpengaruh terhadap akselereasi pembangunan di daerahnya. Semboyan yang berbunyi: "Ing ngarso sung tulodo, ing madyo mangun karso, tut wuri handayani" perlu menjadi slogan yang perlu dihidupkan kembali dalam proses kepemimpinan daerah. Karena sangat diperlukan keteladanan dari pimpinan untuk mengarahkan anak buahnya, diperlukan kreativitas dalam membangun dan menggerakkan bawahan serta diperlukan pengawasan kepada bawahan dalam menyertai mereka ketika bekerja. Pengaruh faktor leadership dalam keberhasilan perilaku seperti yang dikemukakan oleh Hersey, Blanchard, Johnson (1996): " In any situation in which someone is trying to influence the 
behavior of another individual or group leaderhip is occuring leadership. Any times an individual is attempting to influence the behavior of some ones else, that individual is potential leader and the person subjectto the influence attempt is the potential follower, no metter whether that person is the boss, a colleague (associate), a slibordinatses, a friend, a relative or a group"

Dari bahasan di atas yang menjadi kunci untuk mengarah pada perilaku yang mendukung tujuan adalah bagaimana perilaku organisaional yang dilakukan seluruh jajaran aparatur dari level pimpinan sampai aparatur yang berada pada tingkat bawah sekalipun. Ada beberapa persoalan penting untuk mengupayakan perilaku organisasional aparatur dalam rangka pembangunan. Menurut O'Donovan ( 2001) aspek-aspek tersebut meliputi: organizational culture, understanding myself as a manager, performance Apraisal, management development and individual, the managerient of change. Untuk mencapai ideologis birokrasi maka persoalan di atas perlu diketengahkan dalam membahas persoalan peningkatan pembangunan.

\section{Permasalahan Perilaku Organisa- sional Aparatur Pemerintah}

Manusia sebagai subyek pembangunan dan sekaligus menjadi obyek pembangunan harus disadari oleh semua warga negara. Sebagai subyek pembangunan artinya siapa yang melaksanakan pembangunan dan siapa yang beranggung jawab terhadap kemajuan bangsa tidak lain adalah manusia. Sebagai obyek pembangunan artinya untuk siapa keberhasilan pembangunan tersebut akan dirasakan, tidak lain adalah manusia itu sendiri. Dari fungsi ganda tersebut sebenarnya tanggungjawab negara ada dipundak warga negara. Artinya setiap warga negara mempunyai kesadaran sejauh mana kontribusi yang dapat ia berikan pada negara, yang itu semua akhirnya akan kembali pada kesejahteraan manusia sebagai warga negara. Sehingga eksitensi manusia sangat diharapkan dalam keberdayaannya dan kapasitaasnya untuk melaksanakan akselerasi pembangunan daerahnya.

Aparatur pemerintah yaitu warga negera yang bekerja pada instanasi pemerintah. la diangkat oleh negara untuk menjalankan pemerintahan, mewakili negara untuk memberikan pelayanan publik. Dalam proses keterlibatannya pada pelayanan publik, aparatur pemerintah diharapkan mampu melakukan pekerjaan sebagaimana telah diamanatkan. Amanat tersebut harus dilaksanakan dan nantinya dipertanggungjawabkan baik kepada publik maupun pada yang Maha Kuasa atau Tuhannya. Kesadaran untuk 
hal lersebut perlu dihembuskan pada perilaku sehari-hari. Format pertanggungjawaban a,artur, biasanya menggunakan alat kontrol, yang dikenal dengan DP3 (Daftar Penilaian Prestasl Pegawai), yang selama ini masih dipakal untuk mengevaluasi kinerja aparatur pemerintah. Adapun Indikator penilaian meliputi: a) kesetiaan, b) prestasi kerja, c) tanggung jawab d) ketaatan, e) kejujuran, i) kerjasama, g) prakarsa, h) kepemimpinan. Dalam pelaksanaannya untuk monilai indikator tersebut belum mempunyal standar kriteria yang jelas. Socara kualitas nampaknya perlu dilakukan evaluasi kembali mengingat ponilaian yang selama ini dilakukan nampaknya hanya formalitas. Oloh karena itu agar kinerja aparatur benar-benar terukur maka perlu membuat format baru dalam penilaian.

Tuntutan masyarakat terhadap aparatur pomorintah yang bersih dan berwibawa semakin santer. Hal tersobut sojalan dongan meningkatnya pengetaliuan masyarakat dan pengaruh global. Untuk itu pemerintah soliarusnya morespon tuntutan tersobul dengan melakukan upaya perubahan dan peningkatan kualitas monuju pada pomrintahan yang lebih balk. Dalam porkembangan selanjutnya penilaian lembaga pemerintah yang akhir-akhir ini didengungkan dikonal dongan SAKIP (Sitem Akunlabilitas Kinerja Instansi Pemerintah), namun untuk pengembang- an penilaian perilaku aparaturnya secara spesifik nampaknya belum ada.

Sesungguhnya format DP3 tersebut cakupan indikatornya sudah dapat mengukur, namun ada beberapa kelemahan, antara lain belum mempunyai aturan dalam menentukan alat ukurnya. Misalnya saja, aspek-aspek yang diukur melalui DP3 secara teknis oleh atasan langsung berdasar pada pandangan pimpinan, kriterianya berdasar persepsi pimpinan. Apa yang nampak oleh pimpinan itulah sebagai nilai akhir. Sehingga faktor subyektifitas sangat menonjol dan kadang menjadi dominan. Aktivitas tersebut akan mendorong bawahan melakukan pekerjaan hanya faktor pimpinan. Secara psikologis menimbulkan budaya asal bapak senang atau bekerja dengan moral bukan otonom tetapi karena faktor atasan. Yang lebih riskan lagi nampaknya penilaian didasarkan pada faktor senioritas atau lamanya bekerja. Sehingga mereka yang mempunyai lama kerja lebih panjang akan mendapatkan nilai lebih bagus daripada mereka yang masih yunior. Jelas hal tersebut tidak berazaskan pada faktor prestasi. Budaya ini akan menumbuhkan ketidak profesional aparatur pemerintah dalam bekerja

Untuk menumbuhkembangkan apartur pemerintah yang profesional maka salah satı yang menjadi perhatian adalah faktor perilakunya. Bagaimana perilaku tersebut selaras dengan tujuan yang diharapkan oleh 
pemerintah. Perilaku, menurut Hersey, Blanchard, Johnson (1996) merupakan fungsi dari performance, situation atau $B=f(P . S)$. Situational variables terdiri dari: 1) such as followers, time, and job demands, interacting with personal attributes, 2) of the leader, such as directive experience or communication skills, result in leader behavior: such as a diresctive style of leadership, to influence organizational effetiveness 3) which is also influenced by other situational variables. Dari pendapat di atas jelas bahwa perilaku organisasional aparatur pemerintah dipengaruhi oleh berbagai faktor. Faktor tersebut perlu dianalisis keberadaannya ketika terjadi uapaya melakukan perubahan dalam organisasi.

Menurut Kode Etika bagi Petugas Administrasi Negara, seperti dijelaskan oleh The Liang Gie (1998), antara lain secara substansi PNS harus: 1) ada kejujuran, 2) pelayanan prima kepada masyarakat: hormat, sopan, penuh perhatian dan tanggap 3) bekerja dengan keahlian, sikap tidak memihak, efisiensi dan berdaya guna, dll. Untuk dapat mengimplementasikan itu semua maka harus ada komitmen yang dalam dan bahwa nilai-nilai tersebut harus menyatu dalam proses bekerja sehari-hari. Dapat terjadi pula bahwa kondisi aparatur pemerintah yang tidak melakukan salah satu aspek dari kode etik dikarenakan banyak waktu luang yang tidak dimanfaatkan untuk bekerja. Artinya terjadi perbandingan yang tidak seimbang antara volume kerja dengan jumlah kerja. Ur...uk itu dalam hal pengalokasian job diskripsi kepada para pegawai, pimpinan tidak saja melihat pada kemampuan pegawai namun dianalisis sampai pada tingkat kesulitan dan lama penyelesaian pekerjaannya. Pimpinan harus memantau sampai pada implementasinya di lapangan. Dengan demikian akan segera diketahui permasalahan-permasalahan yang terjadi dan dicari solusinya.

Penilaian berdasar SAKIP, yang baru-baru ini dilakukan, yang implementasinya belum merata perlu dilakukan terobosan baru dalam mekanisme penilaian yang lebih mudah. Sehingga akan lebih mudah dalam melakukan penilaian. Pada dasarnya SAKIP merupakan bentuk pertanggungjawaban aparatur pemerintah yang berusaha untuk mendekati ketepatan, kejelasan, dan nyata sebagai upaya untuk terselenggaranya good governance. Prinsip-prinsip good goverment dalam pemerintahan, seperti dirumuskan oleh UNDP 1997 dalam Modul SAKIP (2004) bahwa untuk penyelenggaraan perintahan yang baik maka berbagai karakterisitiknya adalah:

1. Interaction, yakni melibatkan tiga mitra besar: pemerintah, swasta dan masyarakat madani dalam pengelolaan sumber daya ekonomi, sosial dan politik, 
2. Communication, yang di dalamnya terdapat beberapa sistem jejaring dalam proses pengelolaan dan kontribusi terhadap kualitas hasil,

3. Eelf Enforcing Process (proses penguatan diri) antara lain denoan momberikan kontribusi terhadap partisipasi dan menggalakkan kemandirian masyarakat dan memberikan kesempatan unluk kreativitas dan stabilitas untuk berbagai pemerintahan yang baik.

A. Dynamic (dinamis), yakni keseimbangan berbagai unsur kekuatan yang kompleks yang membuahkan persatuan, harmoni, dan kerjasama untuk menumbulikan dan pembangunan berkelanjutan, kedamaian dan keadilan serta kesempatan merata untuk semua sektor dalam masyarakat madani.

5. Dynamic Intordopendency, yakni adanya saling ketergantungan yang dinamis antara pemerintah, kekuatan pasar dan masyarakat madanl.

Morotspon apa yang menjadi ulopla good goverment maka aparalur pemerintah hendaknya menghayall dan mompelajari apa yang monjadi lujuan pemerintah daerahnya, alau misi dan visinya. Dari itu kemudian diojawantahkan pada usaha menyesuaikan perilaku dalam organisasional pemerintahannya. Bekerja yang lidak didasari oleh tujuan yang akan dicapai nampaknya tidak memberikan semangat dan tentu saja hal ini akan sangat dipengaruhi oleh faktor-faktor lain, yang mempengaruhi perilaku aparatur. Dalam melakukan penyesuaian maupun perubahan mengacu pada organisasi bisnis, seperti yang dikemukakan oleh Kolb, Et, al (1995) yakni dengan melakukan proses pembelajaran. Dalam proses pembelajaran melalui tahapa-tahapan yakni: 1) concrete experience is followed by, 2) observation and reflection, which lead to, 3) the formation of abstract concepts and generalization, which lead to, 4) hypotheses to be tested in future action, which in turn lead to new experiences. Melalui tahapan di atas, apa yang direncanakan untuk disesuaikan/dirubah terhadap nilainilai maupun perilaku sangat diperhitungkan berdasarkan data/diagnosis yang benar sehingga tujuan nya dapat tepat dan optimal.

Dalam proses pembelajaran pada para pegawai maka faktor pimpinan sangat berperan. Dalam melakukan perubahan, inovasi tergantung pada pimpinannya. Salah satu hambatan dalam melakukan hal tersebut adalah faktor hierarkhi dalam organisasi. Pegawai bawahan yang mempunyai ide bagus, kadang terhambat adanya hierarkhi, yakni beberapa atasan, yang masingmasing atasan (pimpinan) tersebut mempunyai kekuatan untuk melakukan penolakan. Hambatan dalam 
melakukan perubahan juga tergatung pada pimpinan. Kalau pimpinan tidak mempunyai inisiatif untuk melaukan perubahan maka perilaku baahan juga akan statis. Aspek penting yang perlu diperhatikan, ketika piminan akan melakukan perubahan maka faktor perubahan tersebut haus jelas-jelas diperlukan oleh semua pihak dalam organisasi dan tujuan perubahan harus jelas. Apabila hal tersebut sudah jelas maka pekerjaan selanjutnya adalah melakukan proes perubahan dengan berbagai tekis. Misalnya saja dengan melakukan sosialisasi dan aplikasi.

Instruksi Presiden No. 7 tahun 1999 dan Keputusan Kepala LAN Nomor 239/IX/6/8/2003 teritang Pelapoan Akuntabilitas Kinerja Instansi Pemerintah memberikan legalitas untuk melakukan penilaian terhadap kinerja aparatur pemerintah, yang di dalamnya adalah perilaku organisasional, yang dikenal LAKIP. Untuk menghasilkan LAKIP menggunakan pedoman sistem yaitu SAKIP. SAKIP pada dasarnya adalah instrumen yang digunakan instansi pemerintah dalam memenuhi kewajiban untuk mempertanggungjawabkan keberhasilan dan kegagalan pelaksanaan misi organisasi. Yeremias T. Keban (2004) menjelaskan Akuntabilitas Kinerja diukur melaluj dua pendekatan yaitu: pendekatan perilaku dan pendekatan hasil. Pendekatan perilaku yakni mempelajari perilaku yang berkaitan langsung dengan pelaksanaan tugas aparatur. Pendekatan ini mengamati apakah perilaku aparatur dalam melakukan pekerjaan mampu memberikan hasil tertentu. Pendekatan ini menekankan pada quality of task yang yang menuju pada oriented behavior. Adanya perubahan perilku, metode dan teknik melakukan pekerjaan merupakan penilaian kinerja. Teknik pengukuran dalam pendekatan tersebut dapat melalui BARS (behaviorally anchored rating scales), BOS (Behavioral obsenvation scales) atau OM-B (organizational behavior modivication).

Pendekatan hasil berarti bahwa apakah hasil yang diperoleh, secara kualitas telah sesuai dengan tuntutan dari pihak yang membutuhkan dan telah ditrisbusikan secara proporsional. Indikator dalam pendekatan hasil ditujukan sejauhmana seseorang memberikan kontribusi pada efektivitas organisasinya. Penguruannya dapat melalui produktivitas kerja maupun dengan pendekatan MBO (Management by Obyektif).

\section{Penutup}

Aparatur negara sebagai abdi masyarakat harus mempunyai komitmen yang tinggi untuk bekerja secara profesional karena mereka sebagai change agent dalam pembangunan. Pembangunan akan berhasil salah satunya ditentukan oleh perilaku organisasional aparatur ne- 
gara dalam molakukan tugas sehariharl di kantor. Untuk mewujudkan perilaku aparatur dalami organisasi pemerintahan yang bersih dan berwibawa perlu memahami fungsi dan peran sobagal aparatur pemerintah. Faktor kepemimpinan sangat dominan dalam meningkatkan profesionalitas aparatur. Dalam mengusahakan penyesuaian-penyesuaian perilaku menuju pada perilaku yang diharapkan dalam organisasi maka bawahan haraus mempunyai kejelasan lerhadap perubahan itu sendiri dan lujuannya harus jelas. Penilaian lerliadap perilaku aparatur merupakan input pada penilaian instansi, yang dikenal dengan SAKIP. Pendekalan dalam penilaian tersebut dapal dilerapkan melalui pendekatan perilaku dan pondekatan hasil.

\section{Daflar Pustaka:}

Dochak Latief, 2005. Dalam makalah "Mombangun Sumber Daya Imsanil Yang Cordas, Arif dan Jermoral", Yogyakarta: FIS UNY.
Hersey .Paul, et.al, 1996. Management of Organizational Behavior. California: Prentice Hall.

Kolb A. David, 1995. Organizational Behavior. New Jersey:

Prentice Hall International. Inc.

Modui, 2004. Sistem Akuntabilitas Kinerja Instansi Pemerintah. Jakarta: LAN

The Liang Gie, 1998. Kode Etika Bagi Petugas Pemerintahan. Yogyakarta: Pubib.

Yeremias T. Keban, 2004. Enam Dimensi Strategis Administrasi Publik. Jogjakarta: Gava Media.

\section{Bidata Penulis}

Djihad Hisyam adalah staf pengajar di Program Studi Pendidikan Administrasi Perkantoran di Fakultas IImu Sosial Universitas Negeri Yogyakarta. Menamatkan Studi S1 dan S2 pada Universitas Negeri Yogyakarta 